\title{
On the Stability of an Intermediate Coupled Ocean-Atmosphere Model
}

\author{
Tianxu Zhao ${ }^{1}$ and Guang-an Zou ${ }^{2,3}$ \\ ${ }^{1}$ Department of Mathematics, Baoji University of Arts and Sciences, Baoji 721013, China \\ ${ }^{2}$ Key Laboratory of Ocean Circulation and Wave, Institute of Oceanology, Chinese Academy of Sciences, Qingdao 266071, China \\ ${ }^{3}$ University of Chinese Academy of Sciences, Beijing 100049, China
}

Correspondence should be addressed to Guang-an Zou; zouguangan@gmail.com

Received 24 April 2013; Revised 24 September 2013; Accepted 20 October 2013

Academic Editor: Driss Mehdi

Copyright (c) 2013 T. Zhao and G.-a. Zou. This is an open access article distributed under the Creative Commons Attribution License, which permits unrestricted use, distribution, and reproduction in any medium, provided the original work is properly cited.

The explicit finite difference scheme for solving an intermediate coupled ocean-atmosphere equations has been proposed and discussed. The discrete Fourier analysis within Gerschgorin circle theorem is applied to the stability analysis of this numerical model. The stability criterion that we obtained includes advection, rotation, dissipation, and friction terms, without any assumptions, which is also including the Courant-Friedrichs-Lewy (CFL) condition as a special case. Numerical sensitivity experiments are also carried out by varying the model parameters.

\section{Introduction}

The geophysical motions in both the atmosphere and ocean can be described by partial differential equations (PDEs), in recent years, which have become the very popular and important tools in the study of climate change, weather forecasting, and climate prediction. However, both the coupling process of the atmosphere to the ocean and the corresponding PDEs are very complicated; it is almost impossible to find the exact solution of coupled ocean-atmosphere equations. Research on numerical simulation of the ocean-atmosphere system has aroused many scientists and engineers' interest; a great variety of numerical methods (especially for finite difference method) have been developed to solve this PDEs system [123]. Nevertheless, as we know, there are few people who gives the stability analysis of these complicated numerical models from the mathematical point of view.

The main purpose of this study is to introduce and solve an intermediate coupled ocean-atmosphere PDEs. The stability analysis of numerical method has been taken into consideration by the discrete Fourier analysis combined with Gerschgorin circle theorem. Compared with the time step allowed by the CFL stability criterion, our stability bounds are more accurate and effective. Numerical examples are also presented to test the sensitivity of model. This paper is organized as follows. In the next section, the brief description of an intermediate coupled ocean-atmosphere mathematical model has been introduced. In Section 3, the explicit finite difference scheme is used to solve the PDEs. The stability conditions are given by the numerical analysis in Section 4 . Then the results of experiments are presented and discussed in Section 5. Finally, conclusions are drawn in Section 6.

\section{The Mathematical Model}

The intermediate coupled ocean-atmosphere model used here includes the model of ocean fluid dynamics, the mixed-layer thermodynamics, and the empirical atmospheric model. This coupled ocean-atmosphere model is a modified version of the intermediate coupled model (ICM) developed by Chang [24] and Wang et al. [25], which is an extension of 1.5-layer reduced gravity system that includes the physics of the surface mixed layer and allows the prediction of the sea surface temperature. ICM had been successfully used to the study of El Niño-Southern Oscillation (ENSO), to simulate 
the seasonal cycle of sea surface temperature in the tropical Pacific Ocean [24-28]. The main purpose of present study is to investigate the stability analysis of numerical model from the mathematical analysis point of view.

The upper-ocean flow $\mathbf{u}=(u, v)$ is governed by reducedgravity shallow-water equations:

$$
\begin{aligned}
& \frac{\partial u}{\partial t}+ u \frac{\partial u}{\partial x}+v \frac{\partial u}{\partial y}-f v \\
&=-g^{\prime} \frac{\partial h}{\partial x}+\frac{\tau_{x}}{\rho_{0} H}+K\left(\frac{\partial^{2} u}{\partial x^{2}}+\frac{\partial^{2} u}{\partial y^{2}}\right)-\gamma u \\
& \frac{\partial v}{\partial t}+u \frac{\partial v}{\partial x}+v \frac{\partial v}{\partial y}+f u \\
&=-g^{\prime} \frac{\partial h}{\partial y}+\frac{\tau_{y}}{\rho_{0} H}+K\left(\frac{\partial^{2} v}{\partial x^{2}}+\frac{\partial^{2} v}{\partial y^{2}}\right)-\gamma v \\
& \frac{\partial h}{\partial t}+\frac{\partial H u}{\partial x}+\frac{\partial H v}{\partial y}=0
\end{aligned}
$$

in which $u, v$ are the horizontal velocities; $f=f_{0}+$ $\beta y$ is the Coriolis parameter of the equatorial betaplane approximation, where $f_{0}=2 \Omega \sin \theta, \beta=(2 \Omega \cos \theta) / r_{0}$ and $r_{0}$ is radius of the earth; A density difference between the upper and lower layers results in a reduced gravity constant $g^{\prime}=g\left(\rho_{2}-\rho_{1}\right) / \rho_{0}$ (where $g$ is the acceleration of gravity, $\rho_{1}$ and $\rho_{2}$ are the constant upper and lower layer densities, respectively, and $\rho_{0}$ is a mean density); $\tau_{x}, \tau_{y}$ are the wind stress over the sea surface; $H=D+h$ is the upper layer thickness, where $D$ is the undisturbed layer thickness, $h$ is the interface displacement; $K$ is the lateral eddy viscosity coefficient; $\gamma$ is the interfacial friction coefficient.

Assuming that the effects of compressibility and salinity are of secondary importance in the mixed-layer, the thermodynamics equation can be expressed by

$$
\begin{aligned}
\frac{\partial T}{\partial t}+u_{s} \frac{\partial T}{\partial x}+v_{s} \frac{\partial T}{\partial y}= & \nu\left(\frac{\partial^{2} T}{\partial x^{2}}+\frac{\partial^{2} T}{\partial y^{2}}\right)-\lambda\left(T-T_{0}\right) \\
& +\frac{Q}{\rho_{0} C_{p} H_{0}}-\frac{1}{H_{0}} w_{e} H\left(w_{e}\right)\left(T-T_{e}\right)
\end{aligned}
$$

where $T$ is sea surface temperature (SST), $u_{s}, v_{s}$ are the horizontal velocities in the mixed layer, $T_{0}$ is average SST, $\nu$ is horizontal heat diffusion coefficient, $\lambda$ is adjustable coefficient, $Q$ is downward heat flux, $H_{0}$ is mean depth of mixed layer, $w_{e}$ is the entrainment velocity, $H\left(w_{e}\right)$ is a Heaviside step function of $w_{e}(H(x)=1$, if $x>0, H(x)=0$, if $x<0)$ and $T_{e}$ is entrainment water temperature.

In (4), the horizontal velocity $\mathbf{u}_{s}=\left(u_{s}, v_{s}\right)$ in the surface mixed layer is separated into two components: $\mathbf{u}_{s}=\mathbf{u}+$ $\mathbf{u}_{e}\left(H-H_{0}\right) / H$, where $\mathbf{u}=(u, v)$ is upper-ocean flow velocity, surface Ekman flow $\mathbf{u}_{e}=\left(u_{e}, v_{e}\right)$ is determined by Coriolis force and wind-stress force

$$
\begin{aligned}
& r_{s} u_{e}-f v_{e}=\frac{\tau_{x}}{\rho_{0} H_{0}}, \\
& r_{s} v_{e}-f u_{e}=\frac{\tau_{y}}{\rho_{0} H_{0}}
\end{aligned}
$$

where $r_{s}$ is the Rayleigh friction coefficient.

The entrainment velocity $w_{e}$ is determined as divergence of surface flow $w_{e}=H_{0} \nabla \cdot \mathbf{u}_{s}$ and the temperature of entrained water $T_{e}$ is taked as a linear form:

$$
T_{e}=0.5\left(T+\bar{T}_{50}\right)+2 \frac{\partial T_{50}}{\partial z} h^{\prime}
$$

where $\bar{T}_{50}$ is the observed mean temperature, $\partial T_{50} / \partial z$ is the vertical gradient of $\bar{T}$ at $50 \mathrm{~m}$ depth, and $h^{\prime}$ is the fluctuation of thermocline.

The atmospheric part of the model is written as the sum of the annual mean wind field (or climatology of the monthly mean when the seasonal cycle is involved), coupled feedback, and atmosphere internal variability (see [29]):

$$
\left(\begin{array}{c}
\tau \\
Q
\end{array}\right)=\left(\begin{array}{c}
\bar{\tau} \\
\bar{Q}
\end{array}\right)+\left(\begin{array}{c}
\mu \mathscr{A}\left(T^{\prime}\right) \\
\omega \mathscr{B}\left(T^{\prime}\right)
\end{array}\right)+\left(\begin{array}{l}
\zeta \\
\chi
\end{array}\right),
$$

where $\bar{\tau}$ and $\bar{Q}$ are usually prescribed from observations; $\mathscr{A}$ and $\mathscr{B}$ represent coupling between the atmosphere and ocean, which are empirical functions of SST anomaly; $\mu$ and $\omega$ are the coupling strength. The SST-forced surface wind stress and heat flux are determined by $\mathscr{A}$ and $\mathscr{B}$, which can be written as linear integral operators over the entire domain $\Omega$, that is,

$$
\begin{aligned}
& \mathscr{A}\left(T^{\prime}\right)=\left(\psi, T^{\prime}\right)=\iint_{\Omega} \psi_{\left(x, y ; x^{\prime}, y^{\prime}\right)} T_{\left(x^{\prime}, y^{\prime}, t\right)}^{\prime} d x^{\prime} d y^{\prime}, \\
& \mathscr{B}\left(T^{\prime}\right)=\left(\phi, T^{\prime}\right)=\iint_{\Omega} \phi_{\left(x, y ; x^{\prime}, y^{\prime}\right)} T_{\left(x^{\prime}, y^{\prime}, t\right)}^{\prime} d x^{\prime} d y^{\prime},
\end{aligned}
$$

where $\psi$ and $\phi$ are given by a simple dynamical model of atmosphere.

\section{The Explicit Finite Difference Scheme}

The domain is discretized with a spacing of $\Delta x$ in the $x$ direction, $\Delta y$ in the $y$-direction, and $\Delta t$ in the $t$-direction, and we define $u_{i, j}^{n}=u\left(x_{i}, y_{j}, t_{n}\right)$ with $x_{i}=x_{0}+i \Delta x, y_{j}=$ $y_{0}+j \Delta y, t_{n}=n \Delta t$ for $i, j=0,1, \ldots, n=0,1, \ldots$ The governing equations will be solved on a staggered (Arakawa C-) grid. That is, the $u, v$ are evaluated at the cell boundaries and the $h$ and $T$ points are in the center grids.

The forward difference approximation is used for the time derivative, and the central difference approximation for the 
spatial derivatives. The finite difference operators are defined as

$$
\begin{gathered}
\left(\delta_{t} \alpha\right)_{i, j}=\frac{\alpha_{i, j}^{n+1}-\alpha_{i, j}^{n}}{\Delta t}, \\
\left(\delta_{x} \alpha\right)_{i, j}=\frac{\alpha_{i+1, j}^{n}-\alpha_{i-1, j}^{n}}{2 \Delta x}, \quad\left(\delta_{y} \alpha\right)_{i, j}=\frac{\alpha_{i, j+1}^{n}-\alpha_{i, j-1}^{n}}{2 \Delta y}, \\
\left(\delta_{x}^{2} \alpha\right)_{i, j}=\frac{\alpha_{i+1, j}^{n}-2 \alpha_{i, j}^{n}+\alpha_{i-1, j}^{n}}{\Delta x^{2}} \\
\left(\delta_{y}^{2} \alpha\right)_{i, j}=\frac{\alpha_{i, j+1}^{n}-2 \alpha_{i, j}^{n}+\alpha_{i, j-1}^{n}}{\Delta y^{2}} .
\end{gathered}
$$

Therefore, the difference approximation of the partial differential equations (1)-(4) is given by

$$
\begin{aligned}
&\left(\delta_{t} u\right)_{i+1 / 2, j}+\bar{u}^{*}\left(\delta_{x} u\right)_{i+1 / 2, j}+\bar{v}^{*}\left(\delta_{y} u\right)_{i+1 / 2, j} \\
&-f^{*} v_{i, j+1 / 2}^{n}=-g^{\prime}\left(\delta_{x} \eta\right)_{i, j}+\frac{\tau_{x}}{\rho_{0} H^{*}} \\
&+K\left(\left(\delta_{x}^{2} u\right)_{i+1 / 2, j}+\left(\delta_{y}^{2} u\right)_{i+1 / 2, j}\right)-\gamma u_{i+1 / 2, j}^{n} \\
&\left(\delta_{t} v\right)_{i, j+1 / 2}+\bar{u}^{*}\left(\delta_{x} v\right)_{i, j+1 / 2}+\bar{v}^{*}\left(\delta_{y} v\right)_{i, j+1 / 2} \\
&+f^{*} u_{i+1 / 2, j}^{n}=-g^{\prime}\left(\delta_{y} \eta\right)_{i, j}+\frac{\tau_{y}}{\rho_{0} H^{*}} \\
&+K\left(\left(\delta_{x}^{2} v\right)_{i, j+1 / 2}+\left(\delta_{y}^{2} v\right)_{i, j+1 / 2}\right)-\gamma v_{i, j+1 / 2}^{n}
\end{aligned}
$$

$$
\begin{aligned}
&\left(\delta_{t} h\right)_{i, j}+\bar{u}^{*}\left(\delta_{x} h\right)_{i, j}+\bar{v}^{*}\left(\delta_{y} h\right)_{i, j} \\
&+ H^{*}\left(\left(\delta_{x} u\right)_{i+1 / 2, j}+\left(\delta_{y} v\right)_{i, j+1 / 2}\right)=0 \\
&\left(\delta_{t} T\right)_{i, j}+\bar{u}_{s}^{*}\left(\delta_{x} T\right)_{i, j}+\bar{v}_{s}^{*}\left(\delta_{y} T\right)_{i, j} \\
&=v\left(\left(\delta_{x}^{2} T\right)_{i, j}+\left(\delta_{y}^{2} T\right)_{i, j}\right)-\lambda T_{i, j}^{n} \\
&-T^{*}\left(\left(\delta_{x} u\right)_{i+1 / 2, j}+\left(\delta_{y} v\right)_{i, j+1 / 2}\right)+C\left(T_{0}, Q\right)
\end{aligned}
$$

in which $\bar{u}^{*}=\left(u_{i+1, j}^{n}+u_{i-1, j}^{n}\right) / 2, \bar{v}^{*}=\left(v_{i, j+1}^{n}+v_{i, j-1}^{n}\right) / 2, f^{*}=$ $f_{0}+j \beta \Delta y, H^{*}=D+h_{i, j}^{n}, \bar{u}_{s}^{*}=\bar{u}^{*}+u_{e}\left(H-H_{0}\right) / H, \bar{v}_{s}^{*}=$ $\bar{v}^{*}+v_{e}\left(H-H_{0}\right) / H, T^{*}=H\left(w_{e}\right)\left(T_{i, j}^{n}-T_{e}^{*}\right), C\left(T_{0}, Q\right)=\lambda T_{0}+$ $\left(\mathrm{Q} / \rho_{0} \mathrm{C}_{p} \mathrm{H}_{0}\right)$.

Equations (12) are finite difference equations which represent the original partial differential equations expressed in (1)-(4).

\section{Stability Criterion}

In this section, the stability analysis of numerical schemes will be investigated by the discrete Fourier analysis within Gerschgorin circle theorem. A series of necessary conditions are also obtained. The details are given as follows.

Assuming that $\mathbf{X}_{i, j}^{n}=\left(u_{i+1 / 2, j}^{n}, v_{i, j+1 / 2}^{n}, h_{i, j}^{n}, T_{i, j}^{n}\right)^{T}$, after some rearrangement, (12) can be written as

$$
\begin{aligned}
\mathbf{X}_{i, j}^{n+1}= & A \mathbf{X}_{i+1, j}^{n}+C \mathbf{X}_{i-1, j}^{n}+B \mathbf{X}_{i, j}^{n}+D \mathbf{X}_{i, j+1}^{n} \\
& +E \mathbf{X}_{i, j-1}^{n}+\mathbf{e}_{n}
\end{aligned}
$$

in which $\mathbf{e}_{n}=\left(\tau_{x} / \rho H^{*}, \tau_{y} / \rho H^{*}, 0, C\left(T_{0}, Q\right)\right)^{T}$,

$$
\begin{aligned}
& A=\left(\begin{array}{cccc}
-\frac{\Delta t \bar{u}^{*}}{2 \Delta x}+\frac{\Delta t K}{\Delta x^{2}} & 0 & -\frac{\Delta t g^{\prime}}{2 \Delta x} & 0 \\
0 & -\frac{r \bar{u}^{*}}{2}+\frac{r K}{\Delta x^{2}} & 0 & 0 \\
-\frac{\Delta t H^{*}}{2 \Delta x} & 0 & -\frac{\Delta t \bar{u}^{*}}{2 \Delta x} & 0 \\
-\frac{\Delta t T^{*}}{2 \Delta x} & 0 & 0 & -\frac{\Delta t \bar{u}_{s}^{*}}{2 \Delta x}+\frac{\Delta t v}{\Delta x^{2}}
\end{array}\right) \\
& C=\left(\begin{array}{cccc}
\frac{\Delta t \bar{u}^{*}}{2 \Delta x}+\frac{\Delta t K}{\Delta x^{2}} & 0 & \frac{\Delta t g^{\prime}}{2 \Delta x} & 0 \\
0 & \frac{r \bar{u}^{*}}{2}+\frac{r K}{\Delta x^{2}} & 0 & 0 \\
\frac{\Delta t H^{*}}{2 \Delta x} & 0 & \frac{\Delta t \bar{u}^{*}}{2 \Delta x} & 0 \\
\frac{\Delta t T^{*}}{2 \Delta x} & 0 & 0 & \frac{\Delta t \bar{u}_{s}^{*}}{2 \Delta x}+\frac{\Delta t v}{\Delta x^{2}}
\end{array}\right), \quad B=\left(\begin{array}{cccc}
b_{1} & \Delta t f^{*} & 0 & 0 \\
-\Delta t f^{*} & b_{1} & 0 & 0 \\
0 & 0 & 1 & 0 \\
0 & 0 & 0 & b_{2}
\end{array}\right), \\
& b_{1}=1-\Delta t \gamma-2 \Delta t K\left(\frac{1}{\Delta x^{2}}+\frac{1}{\Delta y^{2}}\right), \quad b_{2}=1-\Delta t \gamma-2 \Delta t \nu\left(\frac{1}{\Delta x^{2}}+\frac{1}{\Delta y^{2}}\right) \text {, }
\end{aligned}
$$




$$
\begin{gathered}
D=\left(\begin{array}{cccc}
-\frac{\Delta t v^{*}}{2 \Delta y}+\frac{\Delta t K}{\Delta y^{2}} & 0 & 0 & 0 \\
0 & -\frac{\Delta t v^{*}}{2 \Delta y}+\frac{\Delta t K}{\Delta y^{2}} & -\frac{\Delta t g^{\prime}}{2 \Delta y} & 0 \\
0 & -\frac{\Delta t H^{*}}{2 \Delta y} & -\frac{\Delta t \bar{v}^{*}}{2 \Delta y} & 0 \\
0 & -\frac{\Delta t T^{*}}{2 \Delta y} & 0 & -\frac{\Delta t v_{s}^{*}}{2 \Delta y}+\frac{\Delta t v}{\Delta y^{2}}
\end{array}\right), \\
E=\left(\begin{array}{cccc}
\frac{\Delta t v^{*}}{2 \Delta y}+\frac{\Delta t K}{\Delta y^{2}} & 0 & 0 & 0 \\
0 & \frac{\Delta t v^{*}}{2 \Delta y}+\frac{\Delta t K}{\Delta y^{2}} & \frac{\Delta t g^{\prime}}{2 \Delta y} & 0 \\
0 & \frac{\Delta t H^{*}}{2 \Delta y} & \frac{\Delta t \bar{v}^{*}}{2 \Delta y} & 0 \\
0 & \frac{\Delta t T^{*}}{2 \Delta y} & 0 & \frac{\Delta t v_{s}^{*}}{2 \Delta y}+\frac{\Delta t v}{\Delta y^{2}}
\end{array}\right) .
\end{gathered}
$$

Definition 1. The two-dimensional discrete Fourier transform of $\mathbf{u} \in \ell_{2}$ is the function $u^{\dagger} \in L_{2}([-\pi, \pi] \times[-\pi, \pi])$ defined by (see[30]):

$$
u^{\dagger}(\xi, \theta)=\frac{1}{2 \pi} \sum_{m, k=-\infty}^{\infty} \exp (-i(m \xi+k \theta)) u_{m, k}
$$

for $\xi, \theta \in[-\pi, \pi]$.

By using the discrete Fourier analysis to transform both sides of (9), we can obtain

$$
\mathbf{X}^{\dagger n+1}(\xi, \theta)=G(\xi, \theta) \mathbf{X}^{\dagger n}(\xi, \theta)+\mathbf{e}_{n}^{\prime},
$$

where $\mathbf{e}_{n}^{\prime}=(1 / 2 \pi) \sum_{m, k=-\infty}^{\infty} \exp (-i(m \xi+k \theta)) \mathbf{e}_{n}$, and the growth matrix

$$
\begin{aligned}
G(\xi, \theta)= & A \exp (i \xi)+C \exp (-i \xi)+B \\
& +D \exp (i \theta)+E \exp (-i \theta) \\
= & \left(\begin{array}{llll}
a_{11} & a_{12} & a_{13} & a_{14} \\
a_{21} & a_{22} & a_{23} & a_{24} \\
a_{31} & a_{32} & a_{33} & a_{34} \\
a_{41} & a_{42} & a_{43} & a_{44}
\end{array}\right)
\end{aligned}
$$

in which

$$
\begin{aligned}
a_{11}= & a_{22}=1-\Delta t \gamma-2 \Delta t K\left(\frac{1}{\Delta x^{2}}+\frac{1}{\Delta y^{2}}\right) \\
& +2 \Delta t K\left(\frac{\cos \xi}{\Delta x^{2}}+\frac{\cos \theta}{\Delta y^{2}}\right)-i \Delta t\left(\frac{\bar{u}^{*} \sin \xi}{\Delta x}+\frac{\bar{v}^{*} \sin \theta}{\Delta y}\right),
\end{aligned}
$$

$$
\begin{gathered}
a_{12}=\Delta t f^{*}, \quad a_{13}=\frac{-i \Delta t g^{\prime} \sin \xi}{\Delta x}, \\
a_{21}=-\Delta t f^{*}, \quad a_{23}=\frac{-i \Delta t g^{\prime} \sin \theta}{\Delta y}, \\
a_{14}=a_{24}=a_{34}=a_{43}=0, \\
a_{31}=\frac{-i \Delta t H^{*} \sin \xi}{\Delta x}, \quad a_{32}=\frac{-i \Delta t H^{*} \sin \theta}{\Delta y}, \\
a_{33}=1-i \Delta t\left(\frac{\bar{u}^{*} \sin \xi}{\Delta x}+\frac{\bar{v}^{*} \sin \theta}{\Delta y}\right), \\
a_{41}=\frac{-i \Delta t T^{*} \sin \xi}{\Delta x}, \quad a_{42}=\frac{-i \Delta t T^{*} \sin \theta}{\Delta y}, \\
a_{44}=1-\Delta t \lambda-2 \Delta t v\left(\frac{1}{\Delta x^{2}}+\frac{1}{\Delta y^{2}}\right) \\
+2 \Delta t \nu\left(\frac{\cos \xi}{\Delta x^{2}}+\frac{\cos \theta}{\Delta y^{2}}\right)-i \Delta t\left(\frac{\bar{u}_{s}^{*} \sin \xi}{\Delta x}+\frac{\bar{v}_{s}^{*} \sin \theta}{\Delta y}\right) .
\end{gathered}
$$

Theorem 2. Let $\rho(G)$ be the spectral radius of the matrix $G$. If there exist constants $\Delta x_{0}, \Delta y_{0}, \Delta t_{0}$, and $C$, independent of $\Delta x$, $\Delta y, \Delta t$, and $\xi, \theta$, such that

$$
|\rho(G)| \leq 1+C \Delta t
$$

for $0<\Delta t \leq \Delta t_{0}, 0<\Delta x \leq \Delta x_{0}$, and $0<\Delta y \leq \Delta y_{0}$, and for all $\xi, \theta \in[-\pi, \pi]$, then the scheme (18) is stable in the $\ell_{2}$ norm.

Theorem 3 (Gerschgorin Circle Theorem, see [31]). Let A be a complex $n \times n$ matrix, $a_{i j}$ are elements of matrix $A$. For each eigenvalue $\lambda$ of $A$, there exists an s such that

$$
\left|\lambda-a_{s s}\right| \leq \rho_{s}, \quad s=1,2, \ldots, n,
$$

where $\rho_{s}=\sum_{j=1, j \neq s}^{n}\left|a_{s j}\right|$ are the sum of the absolute values of the elements in the sth row except for the diagonal element. 
By Gerschgorin Circle Theorem, if $\lambda$ is an eigenvalue of $G$, we have

$$
\begin{aligned}
&\left|\lambda-a_{11}\right| \leq\left|a_{12}\right|+\left|a_{13}\right|=\left|\Delta t f^{*}\right|+\left|\frac{-i \Delta t g^{\prime} \sin \xi}{\Delta x}\right|, \\
&\left|\lambda-a_{22}\right| \leq\left|a_{21}\right|+\left|a_{23}\right|=\left|-\Delta t f^{*}\right|+\left|\frac{-i \Delta t g^{\prime} \sin \theta}{\Delta y}\right|, \\
&\left|\lambda-a_{33}\right| \leq\left|a_{31}\right|+\left|a_{32}\right| \\
&=\left|\frac{-i \Delta t H^{*} \sin \xi}{\Delta x}\right|+\left|\frac{-i \Delta t H^{*} \sin \theta}{\Delta y}\right|, \\
&\left|\lambda-a_{44}\right| \leq\left|a_{41}\right|+\left|a_{42}\right| \\
&=\left|\frac{-i \Delta t T^{*} \sin \xi}{\Delta x}\right|+\left|\frac{-i \Delta t T^{*} \sin \theta}{\Delta y}\right| .
\end{aligned}
$$

Using the backwards triangular inequality, we take $C<$ $1 / \Delta t$, if the time-space steps and model parameters yield the following conditions:

$$
\begin{gathered}
\frac{\Delta t}{\Delta x}\left(\left|\bar{u}^{*}\right|+g^{\prime}\right)+\frac{\Delta t\left|\bar{v}^{*}\right|}{\Delta y}+\Delta t\left(\left|f^{*}\right|+|\gamma|\right) \\
+4 \Delta t K\left(\frac{1}{\Delta x^{2}}+\frac{1}{\Delta y^{2}}\right)<1, \\
\frac{\Delta t}{\Delta y}\left(\left|\bar{v}^{*}\right|+g^{\prime}\right)+\frac{\Delta t\left|\bar{u}^{*}\right|}{\Delta x}+\Delta t\left(\left|f^{*}\right|+|\gamma|\right) \\
+4 \Delta t K\left(\frac{1}{\Delta x^{2}}+\frac{1}{\Delta y^{2}}\right)<1, \\
\frac{\Delta t}{\Delta x}\left(\left|\bar{u}^{*}\right|+\left|H^{*}\right|\right)+\frac{\Delta t}{\Delta y}\left(\left|\bar{v}^{*}\right|+\left|H^{*}\right|\right)<1, \\
\frac{\Delta t}{\Delta x}\left(\left|\bar{u}_{s}^{*}\right|+\left|T^{*}\right|\right)+\frac{\Delta t}{\Delta y}\left(\left|\bar{v}_{s}^{*}\right|+\left|T^{*}\right|\right)+\Delta t|\lambda| \\
+4 \Delta t v\left(\frac{1}{\Delta x^{2}}+\frac{1}{\Delta y^{2}}\right)<1 .
\end{gathered}
$$

Then we have $|\lambda| \leq 1+C \Delta t$, so the explicit finite difference scheme (13) is conditionally stable. Consequently, the timestep size satisfies the following inequality:

$$
\Delta t<\min \left\{\frac{1}{a}, \frac{1}{b}, \frac{1}{c}, \frac{1}{d}\right\}
$$

In which $a=(1 / \Delta x)\left(\max \left|\bar{u}^{*}\right|+g^{\prime}\right)+\left(\max \left|\bar{v}^{*}\right| / \Delta y\right)+$ $\left(\left|f^{*}\right|+|\gamma|\right)+4 K\left(\left(1 / \Delta x^{2}\right)+\left(1 / \Delta y^{2}\right)\right), b=(1 / \Delta y)\left(\max \left|\bar{v}^{*}\right|+\right.$ $\left.g^{\prime}\right)+\left(\max \left|\bar{u}^{*}\right| / \Delta x\right)+\left(\left|f^{*}\right|+|\gamma|\right)+4 K\left(\left(1 / \Delta x^{2}\right)+\left(1 / \Delta y^{2}\right)\right)$, $c=(1 / \Delta x)\left(\max \left|\bar{u}^{*}\right|+\left|H^{*}\right|\right)+(1 / \Delta y)\left(\max \left|\bar{v}^{*}\right|+\left|H^{*}\right|\right), d=$ $(1 / \Delta x)\left(\max \left|\bar{u}_{s}^{*}\right|+\max \left|T^{*}\right|\right)+(1 / \Delta y)\left(\max \left|\bar{v}_{s}^{*}\right|+\max \left|T^{*}\right|\right)+$ $|\lambda|+4 \nu\left(\left(1 / \Delta x^{2}\right)+\left(1 / \Delta y^{2}\right)\right)$.
TABLE 1: The values of parameters in the model.

\begin{tabular}{lc}
\hline Parameter & Value \\
\hline$\Omega$ & $7.29 \times 10^{-5} \mathrm{~s}^{-1}$ \\
$D$ & $100 \mathrm{~m}$ \\
$K$ & $2.5 \times 10^{-4} \mathrm{~m}^{2} \mathrm{~s}^{-1}$ \\
$\nu$ & $2.5 \times 10^{-4} \mathrm{~m}^{2} \mathrm{~s}^{-1}$ \\
$H_{0}$ & $50 \mathrm{~m}$ \\
$g^{\prime}$ & $4.17 \mathrm{~cm} \mathrm{~s}^{-2}$ \\
$\rho_{0}$ & $1000 \mathrm{~kg} \mathrm{~m}^{-3}$ \\
$\gamma$ & $2.5 \times 10^{-3} \mathrm{day}^{-1}$ \\
$\lambda$ & $5 \times 10^{-3} \mathrm{day}^{-1}$ \\
$C_{p}$ & $4.2 \times 10^{3} \mathrm{~J} \mathrm{Kg}^{-1} \mathrm{~K}^{-1}$ \\
\hline
\end{tabular}

When the rotation, dissipation, and friction terms are neglected, we have

$$
\begin{aligned}
\Delta t<\min \{ & \left(\frac{\Delta x}{\max \left|\bar{u}^{*}\right|}+\frac{\Delta y}{\max \left|\bar{v}^{*}\right|}\right), \\
& \left.\left(\frac{\Delta x}{\max \left|\bar{u}_{s}^{*}\right|}+\frac{\Delta y}{\max \left|\bar{v}_{s}^{*}\right|}\right)\right\} .
\end{aligned}
$$

This is Courant-Friedrichs-Lewy (CFL) condition [3234]; obviously, it is only a special case in our results.

\section{Numerical Results}

Sensitivity studies are a necessary and important part of the developments of mathematical models of geophysical fluid systems. They can help to reveal aspects of the model that will most profitably benefit from further refinement, as well as providing insights into the fundamental dynamics of these complicated fluid systems [18]. In this study, we consider the sensitivity of an intermediate coupled ocean-atmosphere model to change in the Coriolis parameters $f$, the interfacial friction coefficient $\gamma$, the lateral eddy viscosity coefficient $K$, and the adjustable coefficient $\lambda$. Parameter values are shown in Table 1.

The model domain extends form $30^{\circ} \mathrm{S}$ to $30^{\circ} \mathrm{N}$ in latitude and from $120^{\circ} \mathrm{E}$ to $80^{\circ} \mathrm{W}$ in longitude. The model resolution is $2^{\circ}$ in $x$ direction and $1^{\circ}$ in $y$ direction. Free-slip boundary conditions in velocity and no-flux boundary conditions in temperature are used in the ocean model.

5.1. Example 1. According to the stability criterion (25), we obtain $\Delta t<14306 \mathrm{~s}$; from the CFL condition, we have $\Delta t<$ $189031 \mathrm{~s}$.

Running the model for one year, Figure 1 gives the results of zonal velocity $u$ and meridional velocity $v$ (at the latitude $\left.0^{\circ} \mathrm{N}\right)$ by changing with time-step $\Delta t(\mathrm{dt})$.

When we take $\Delta t=14306 \mathrm{~s}$, Figure 2 shows the results of zonal velocity $u$ at the latitude $0^{\circ} \mathrm{N}$ and the longitude $180^{\circ} \mathrm{E}$, respectively, and the maximum speed is $3.5 \mathrm{~m} / \mathrm{s}$, which is not in accordance with the actual condition. When we take $\Delta t>$ $14306 \mathrm{~s}$, the results overflow. The range of the CFL condition is too big; that is to say, the CFL condition is less strict and accurate than our results. 

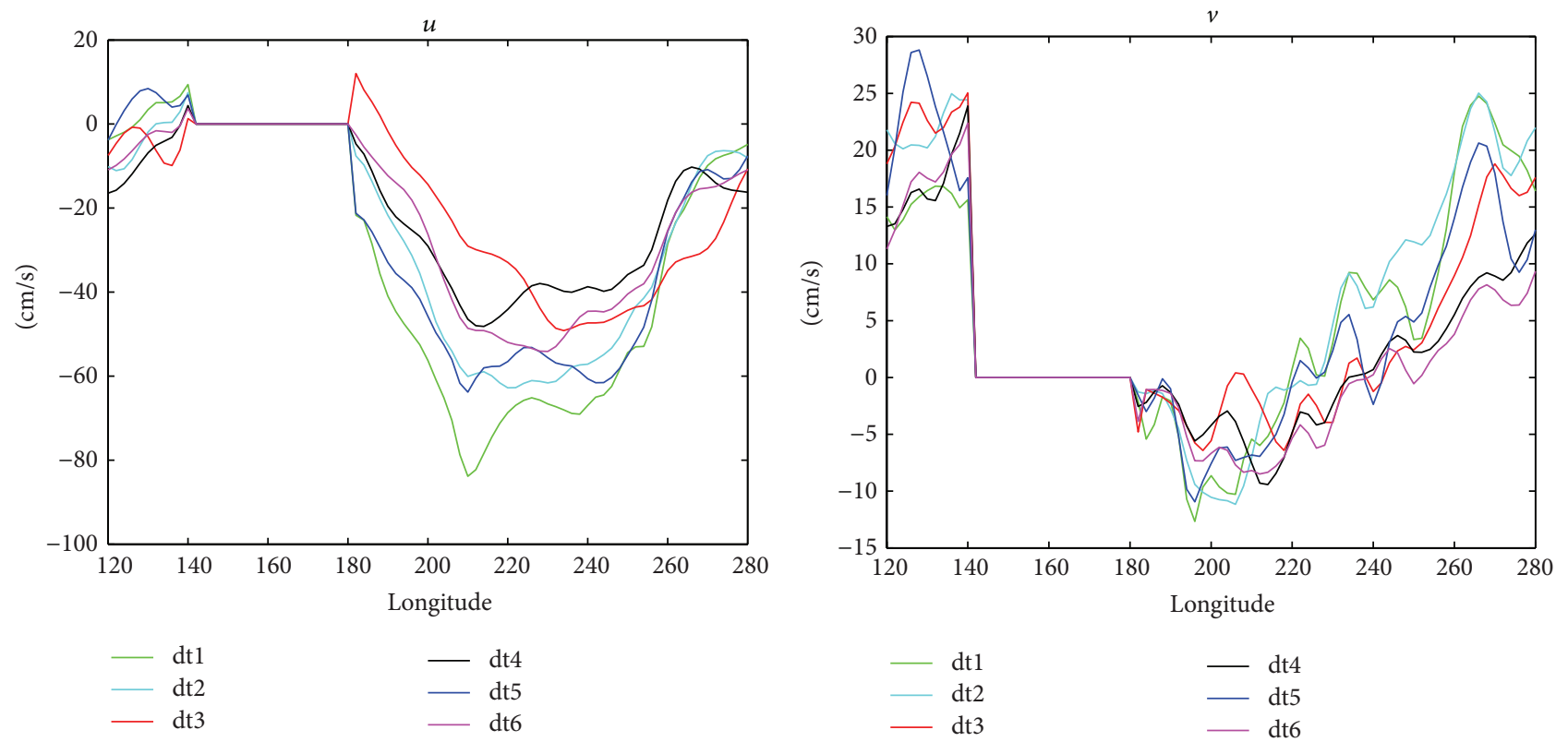

FIGURE 1: The figures show the values of the zonal velocity $u$ and the meridional velocity $v$ at the latitude $0^{\circ} \mathrm{N}$, with $\mathrm{dt} 1=600 \mathrm{~s} ; \mathrm{dt} 2=1200 \mathrm{~s}$; $\mathrm{dt} 3=3600 \mathrm{~s} ; \mathrm{dt} 4=7200 \mathrm{~s} ; \mathrm{dt} 5=10800 \mathrm{~s} ; \mathrm{dt} 6=12000 \mathrm{~s}$.

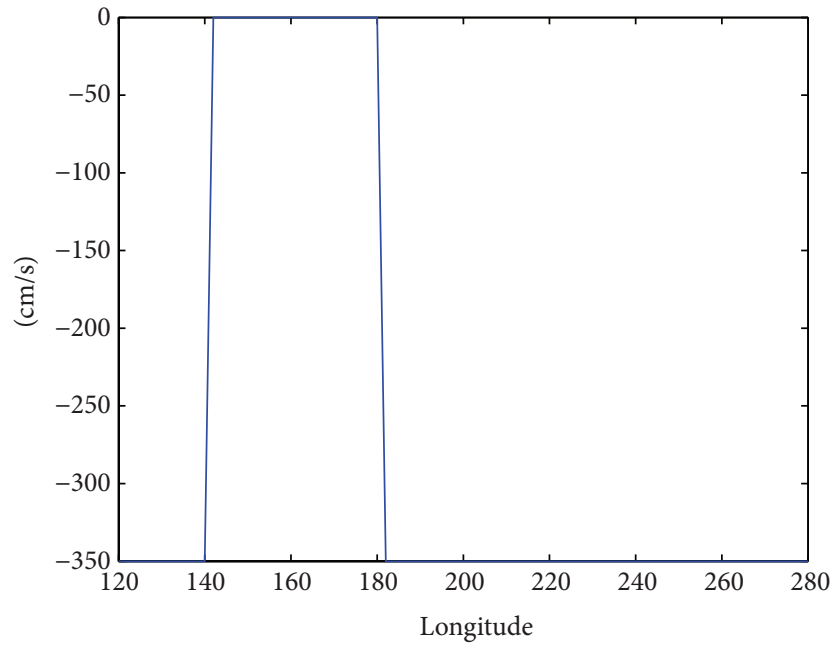

(a)

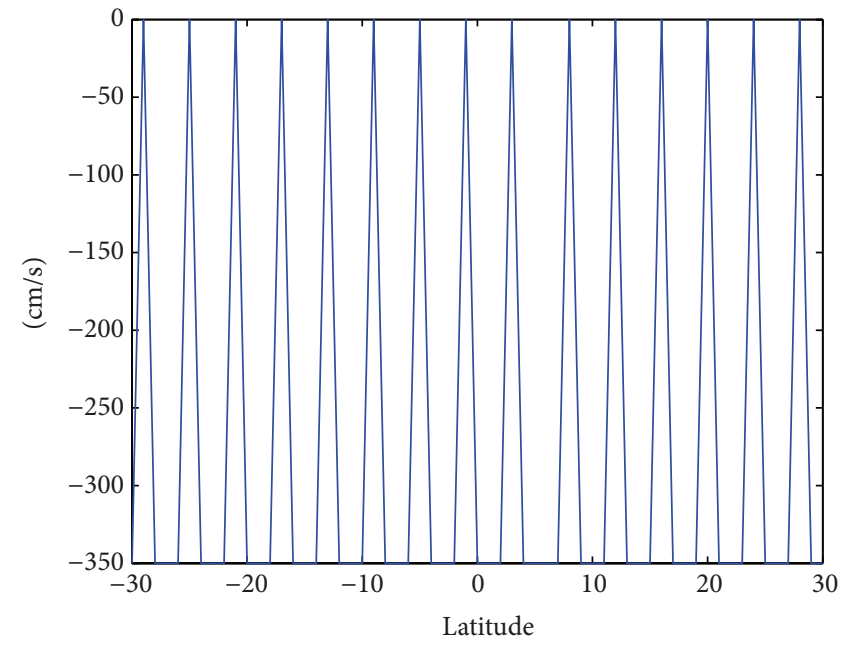

(b)

FIgUre 2: (a) shows the values of the zonal velocity $u$ at the latitude $0^{\circ} \mathrm{N}$, and (b) at the longitude $180^{\circ} \mathrm{E}$.

5.2. Example 2. In this numerical tests, we will discuss the sensitivity of model parameters. The model has been run for one year, and we take the time-step size $\Delta t=10800 \mathrm{~s}$. The variable changes that result from the variation of coefficients are only given one (as well as the others) in each experiments on the model simulation.

Figure 3 gives the results of sea surface temperature (SST) with the variation of Coriolis parameters (the variation of the angle $\theta$ (theta)) at the latitude $0^{\circ} \mathrm{N}$ and the longitude $180^{\circ} \mathrm{E}$, respectively. Figure 4 displays the sea surface height
(SSH) with the variation of the interfacial friction coefficient $\gamma$ (gamma). Figure 5 shows the meridional velocity $u$ with the variation of lateral eddy viscosity coefficient $K$. Figure 6 exhibits the meridional velocity $v(\mathrm{~cm} / \mathrm{s})$ with the variation of adjustable coefficient $\lambda$ (lambda).

We find that Coriolis parameters, lateral eddy viscosity coefficient, interfacial friction coefficient, and adjustable coefficient have an impact on the model evolutions. Therefore, taking the CFL condition as the stability criterion alone is not reasonable. On the other hand, it is also important 

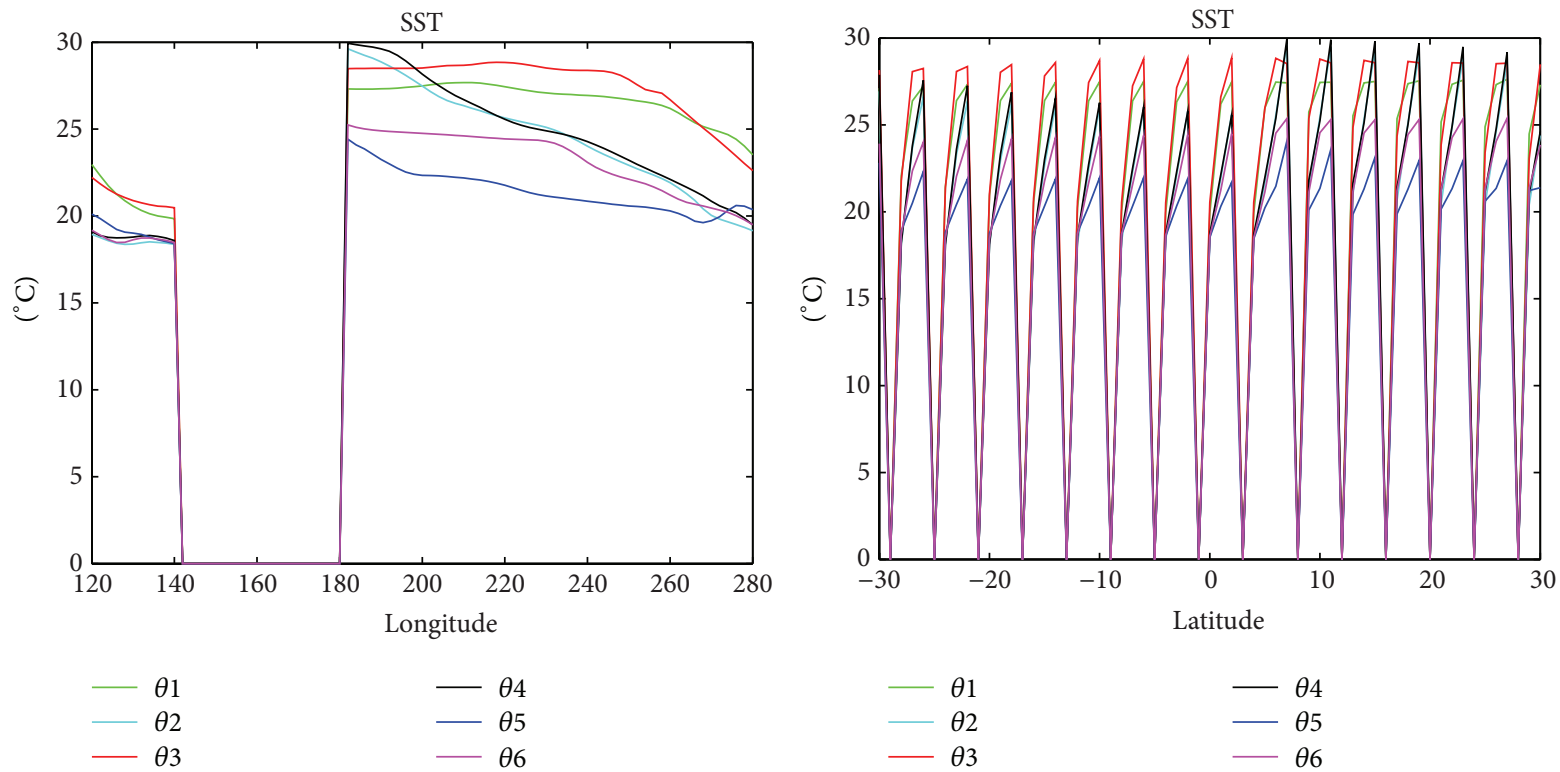

Figure 3: The figure gives the results of SST $\left({ }^{\circ} \mathrm{C}\right.$ ) with the variation of angle $\theta$ (theta), in which $\theta 1=0^{\circ} ; \theta 2=30^{\circ} ; \theta 3=45^{\circ} ; \theta 4=60^{\circ} ; \theta 5=90^{\circ}$; $\theta 6=135^{\circ}$.
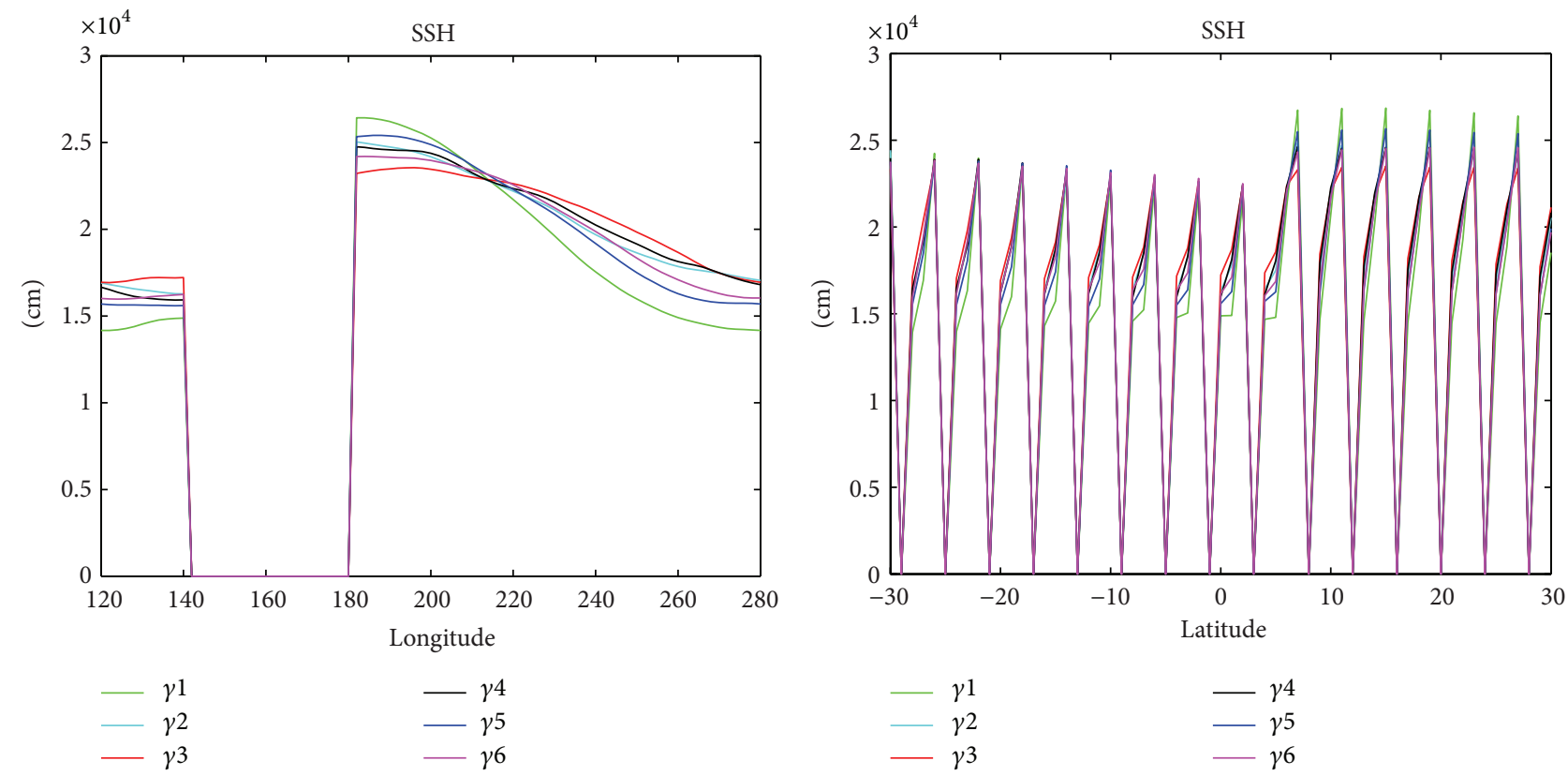

FIGURE 4: The figure gives the results of SSH with the variation of $\gamma$ (gamma), in which $\gamma 1=1.5 \times 10^{-3}$ day $^{-1} ; \gamma 2=2.5 \times 10^{-3}$ day $^{-1}$; $\gamma^{3}=3.5 \times 10^{-3}$ day $^{-1} ; \gamma 4=4.5 \times 10^{-3}$ day $^{-1} ; \gamma^{5}=5.5 \times 10^{-3}$ day $^{-1} ; \gamma 6=6.5 \times 10^{-3}$ day $^{-1}$.

to derive future model developments and test the numerical model.

\section{Conclusion}

The present study provides an intermediate coupled oceanatmosphere model, and the stability criterion are also obtained for the choice of time and space steps size, in order to ensure the errors made at one time step of the calculation do not cause the errors to increase as the computations are continued. Our results are effective and reasonable, which are including CFL condition. Numerical sensitivity experiments show that the Coriolis parameters, lateral eddy viscosity coefficient, interfacial friction coefficient, and adjustable coefficient are important to the stability of model. However, external forcing also plays a dominant role in oceanatmosphere system, for example, wind stress curl, heat flux, and so forth [18, 35, 36]; are not reported in this study. 

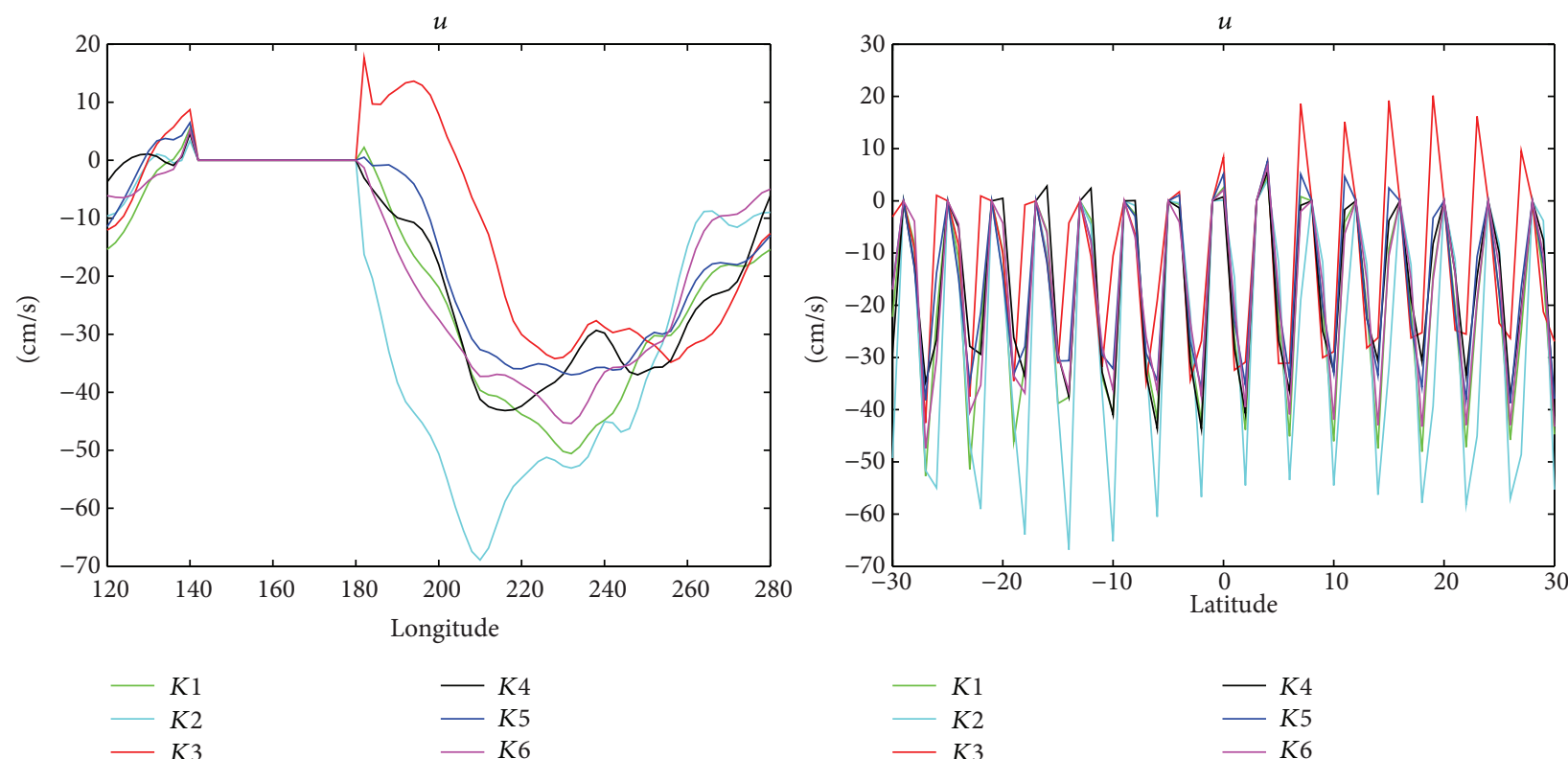

FIGURE 5: The figure gives the results of meridional velocity $u$ with the variation of $K$, in which $K 1=2 \times 10^{-3} \mathrm{~m}^{2} \mathrm{~s}^{-1} ; K 2=3 \times 10^{-3} \mathrm{~m}^{2} \mathrm{~s}^{-1}$; $K 3=4 \times 10^{-3} \mathrm{~m}^{2} \mathrm{~s}^{-1} ; K 4=5 \times 10^{-3} \mathrm{~m}^{2} \mathrm{~s}^{-1} ; K 5=6 \times 10^{-3} \mathrm{~m}^{2} \mathrm{~s}^{-1} ; K 6=7 \times 10^{-3} \mathrm{~m}^{2} \mathrm{~s}^{-1}$.
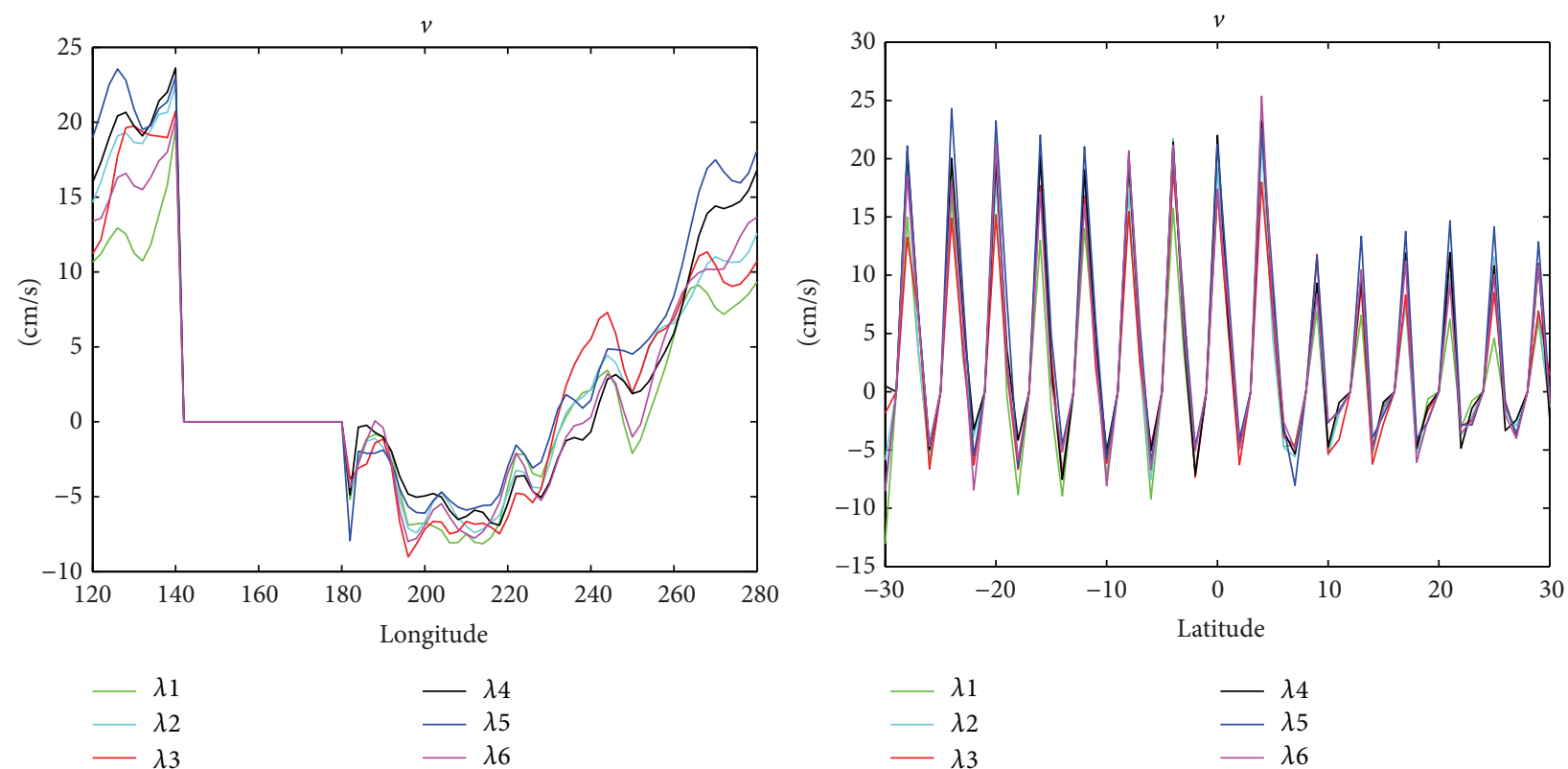

FIGURE 6: The figure shows the results of meridional velocity $v(\mathrm{~cm} / \mathrm{s})$ with the variation of $\lambda$ (lambda), where $\lambda 1=3 \times 10^{-3}$ day $^{-1}$; $\lambda 2=$ $4 \times 10^{-3}$ day $^{-1} ; \lambda 3=5 \times 10^{-3}$ day $^{-1} ; \lambda 4=6 \times 10^{-3}$ day $^{-1} ; \lambda 5=7 \times 10^{-3}$ day $^{-1} ; \lambda 6=8 \times 10^{-3}$ day $^{-1}$.

Based on the parameters sensitivity studies, the present study allows understanding the physical mechanism of the oceanatmosphere system more clearly. This intermediate coupled ocean-atmosphere model will be used for further study, and the method of stability analysis in present work can also be used to the stability study of earth system numerical model.

\section{Acknowledgments}

The authors thank the editor and the reviewers for their helpful and constructive suggestions.

\section{References}

[1] K. Bryan, "A numerical method for the study of the circulation of the world ocean," Journal of Computational Physics, vol. 4, no. 3, pp. 347-376, 1969.

[2] R. N. Miller, Numerical Modeling of Ocean Circulation, Cambridge University Press, New York, NY, USA, 2007.

[3] C. Chen, H. Liu, and R. C. Beardsley, "An unstructured grid, finite-volume, three-dimensional, primitive equations ocean model: application to coastal ocean and estuaries," Journal of 
Atmospheric and Oceanic Technology, vol. 20, no. 1, pp. 159-186, 2003.

[4] A. F. Blumberg and G. L. Mellor, "A description of a three-dimensional coastal ocean circulation model," in ThreeDimensional Coastal Ocean Models, N. S. Heaps, Ed., vol. 4 of Coastal and Estuarine Series, pp. 1-16, American Geophysical Union, 1987.

[5] S. Danilov, "Two finite-volume unstructured mesh models for large-scale ocean modeling," Ocean Modelling, vol. 47, pp. 14-25, 2012.

[6] A. M. Davies, J. Xing, and J. E. Jones, "A model study of tidal distributions in the Celtic and Irish Sea regions determined with finite volume and finite element models," Ocean Dynamics, vol. 61, no. 10, pp. 1645-1667, 2011.

[7] J. Eric Jones and A. M. Davies, "Application of a finite element model to the computation of tides in the Mersey Estuary and Eastern Irish Sea," Continental Shelf Research, vol. 30, no. 5, pp. 491-514, 2010.

[8] Z. Q. Yang and T. R. Khangaonkar, "Modeling tidal circulation and stratification in Skagit River estuary using an unstructured grid ocean model," Ocean Modelling, vol. 28, no. 1-3, pp. 34-49, 2009.

[9] Y. L. Zhang and A. M. Baptista, "SELFE: a semi-implicit Eulerian-Lagrangian finite-element model for cross-scale ocean circulation," Ocean Modelling, vol. 21, no. 3-4, pp. 71-96, 2008.

[10] Q. Wang, S. Danilov, and J. Schröter, "Finite element ocean circulation model based on triangular prismatic elements, with application in studying the effect of topography representation," Journal of Geophysical Research, vol. 113, no. C5, 2008.

[11] S. Danilov, G. Kivman, and J. Schröter, "A finite-element ocean model: principles and evaluation," Ocean Modelling, vol. 6, no. 2, pp. 125-150, 2004.

[12] R. Bleck, "An oceanic general circulation model framed in hybrid isopycnic-Cartesian coordinates," Ocean Modelling, vol. 4, no. 1, pp. 55-88, 2002.

[13] G. J. Fix, "Finite element models for ocean circulation problems," SIAM Journal on Applied Mathematics, vol. 29, no. 3, pp. 371-387, 1975.

[14] R. Gerdes, "A primitive equation ocean circulation model using a general vertical coordinate transformation 1 . Description and testing of the model," Journal of Geophysical Research, vol. 98, no. 8, pp. 14683-14701, 1993.

[15] S. M. Griffies, C. Böning, F. O. Bryan et al., "Developments in ocean climate modelling," Ocean Modelling, vol. 2, no. 3-4, pp. 123-192, 2000.

[16] D. Haidvogel, E. Curchitser, M. Iskandarani, R. Hughes, and M. Taylor, "Global modeling of the ocean and atmosphere using the spectral element method," Atmosphere-Ocean, vol. 35, pp. 505531, 1997.

[17] R. A. Walters, "Design considerations for a finite element coastal ocean model," Ocean Modelling, vol. 15, no. 1-2, pp. 90-100, 2006.

[18] F. Bryan, "Parameter sensitivity of primitive equation ocean general circulation models," Journal of Physical Oceanography, vol. 17, no. 7, pp. 970-985, 1987.

[19] A. Rosati and K. Miyakoda, "A general circulation model for upper ocean simulation," Journal of Physical Oceanography, vol. 11, pp. 1601-1626, 1988.

[20] K. Bryan, S. Manabe, and R. C. Pacanowski, "A global oceanatmosphere climate model. Part II. The oceanic circulation," Journal of Physical Oceanography, vol. 5, pp. 30-46, 1975.
[21] Y.-J. Han, "A numerical world ocean general circulation model. Part II. A baroclinic experiment," Dynamics of Atmospheres and Oceans, vol. 8, no. 2, pp. 141-172, 1984.

[22] M. J. Roberts and R. A. Wood, "Topographic sensitivity studies with a Bryan-Cox-type ocean model," Journal of Physical Oceanography, vol. 27, no. 5, pp. 823-836, 1997.

[23] J. A. T. Bye, "Coupling ocean-atmosphere models," EarthScience Reviews, vol. 40, no. 1-2, pp. 149-162, 1996.

[24] P. Chang, "A study of the seasonal cycle of sea surface temperature in the tropical Pacific Ocean using reduced gravity models," Journal of Geophysical Research, vol. 99, no. 4, pp. 7725-7741, 1994.

[25] B. Wang, T. Li, and P. Chang, "An intermediate model of the tropical Pacific Ocean," Journal of Physical Oceanography, vol. 25, pp. 1599-1616, 1995.

[26] P. Chang, B. Wang, T. Li, and L. Ji, "Interactions between the seasonal cycle and the Southern Oscillation-frequency entrainment and chaos in a coupled ocean-atmosphere model," Geophysical Research Letters, vol. 21, no. 25, pp. 2817-2820, 1994.

[27] P. Chang, L. Ji, B. Wang, and T. Li, "Interactions between the seasonal cycle and El Nino-Southern Oscillation in an intermediate coupled ocean-atmosphere model," Journal of the Atmospheric Sciences, vol. 52, no. 13, pp. 2353-2372, 1995.

[28] P. Chang, L. Ji, H. Li, and M. Flügel, "Chaotic dynamics versus stochastic processes in El Niño-Southern Oscillation in coupled ocean-atmosphere models," Physica D, vol. 98, no. 2-4, pp. 301320, 1996.

[29] F. M. Wang and P. Chang, "A linear stability analysis of couple tropical Atlantic variability," Journal of Climate, vol. 21, no. 11, pp. 2421-2436, 2008.

[30] J. W. Thomas, Numerical Partial Differential Equations: Finite Difference Methods, Springer, New York, NY, USA, 1997.

[31] G. H. Golub and C. F. van Loan, Matrix Computations, Johns Hopkins University Press, Baltimore, Md, USA, 3rd edition, 1996.

[32] J. C. Strikwerda, Finite Difference Schemes and Partial Differential Equations, Brooks Cole, Pacific Grove, Calif, USA, 1989.

[33] D. R. Durran, Numerical Methods for Fluid Dynamics: With Applications to Geophysics, vol. 32, Springer, New York, NY, USA, 2nd edition, 2010.

[34] R. Heihes and D. A. Randall, "Numerical integration of the shallow-water equations on a twisted icosahedral grid. Part I: basic design and results of tests," Monthly Weather Review, vol. 123, no. 6, pp. 1862-1880, 1995.

[35] W. G. Large, G. Danabasoglu, S. C. Doney, and J. C. Mcwilliams, "Sensitivity to surface forcing and boundary layer mixing in a global ocean model: annual-mean climatology," Journal of Physical Oceanography, vol. 27, no. 11, pp. 2418-2447, 1997.

[36] D. G. Wright and T. F. Stocker, "Sensitivities of a zonally averaged global ocean circulation model," Journal of Geophysical Research, vol. 97, no. 8, pp. 12707-12730, 1992. 


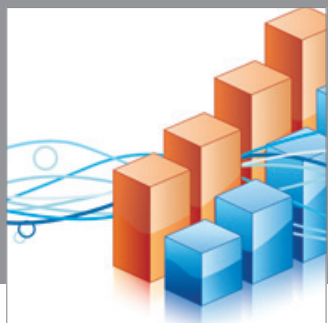

Advances in

Operations Research

mansans

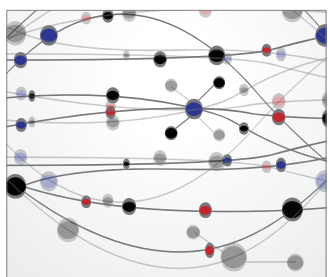

The Scientific World Journal
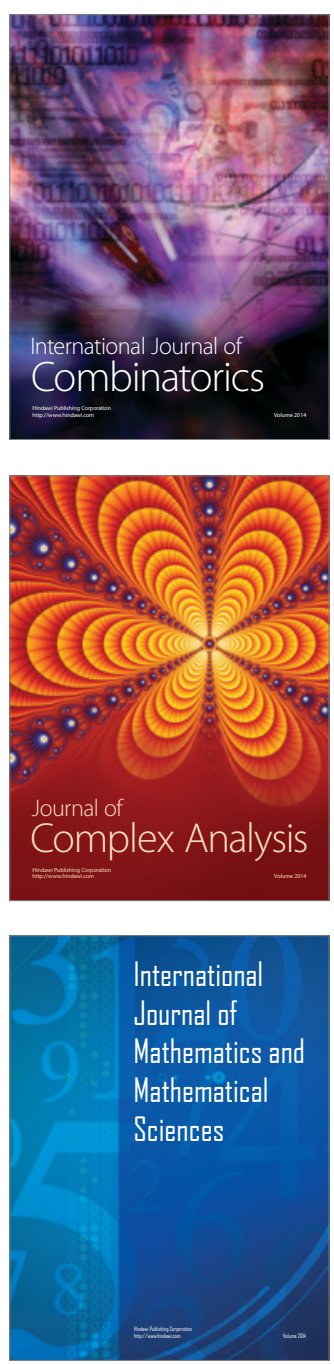
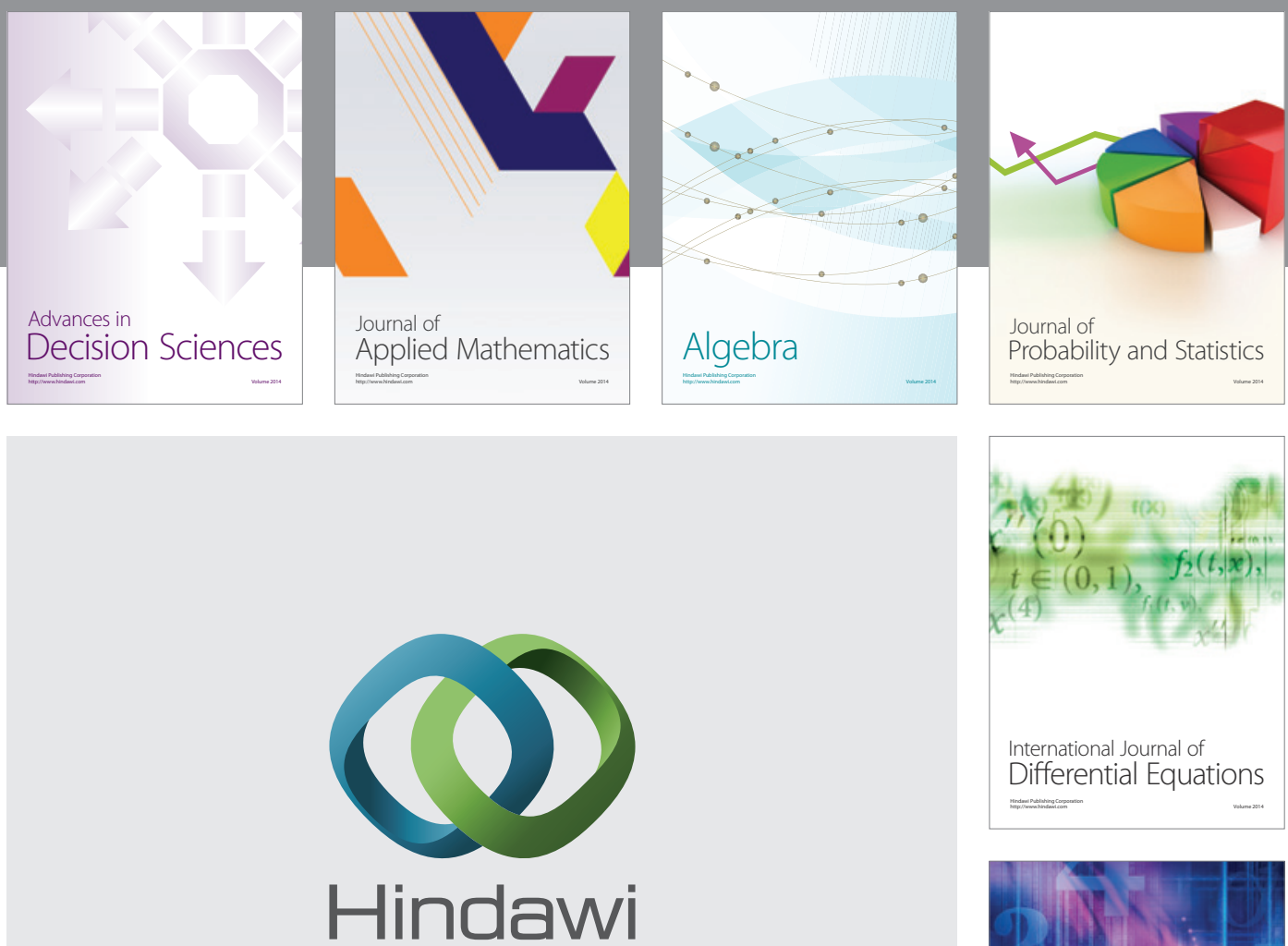

Submit your manuscripts at http://www.hindawi.com
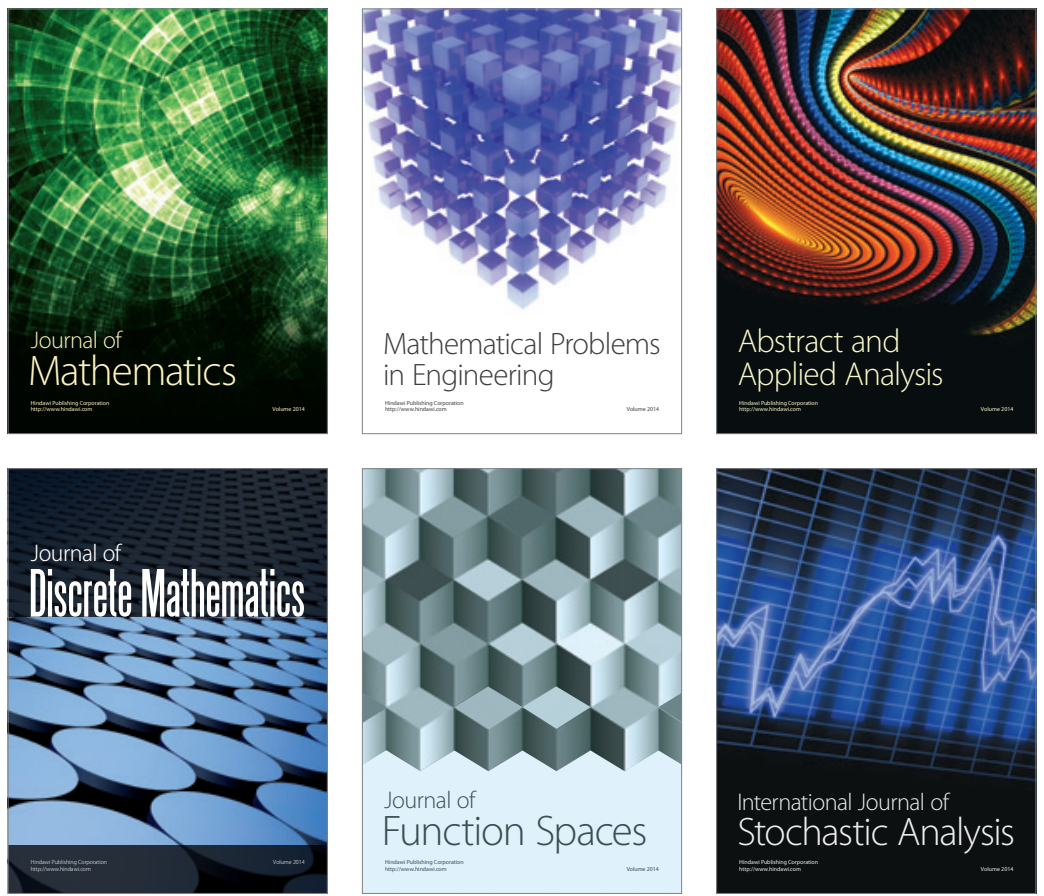

Journal of

Function Spaces

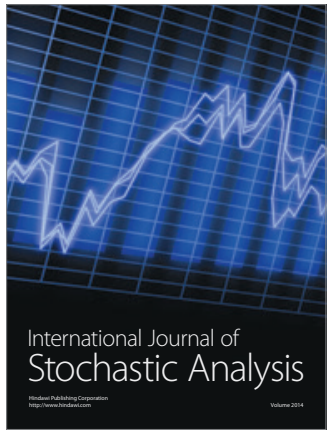

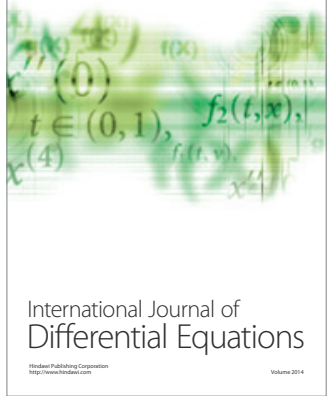
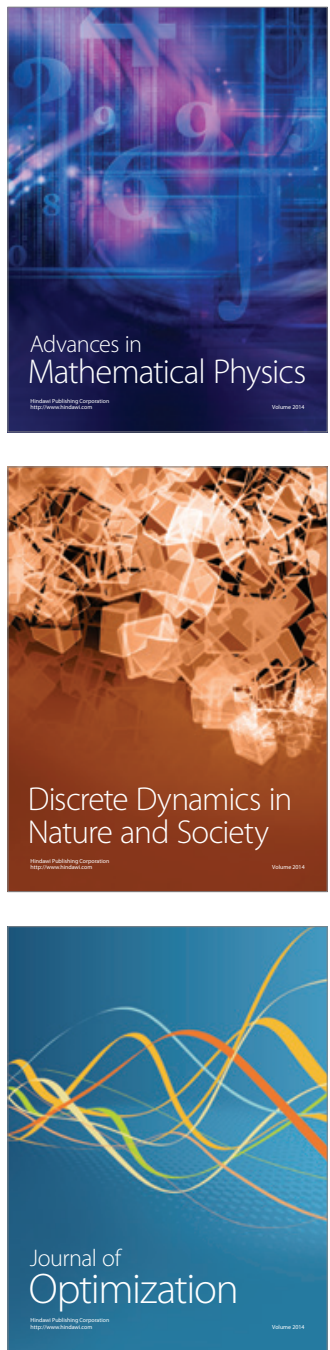